\title{
The Teaching Excellence Framework: Perpetual Pedagogical Control in Postwelfare Capitalism
}

Conor Heaney, Hollie Mackenzie

\begin{abstract}
In this paper, we argue that Success as a Knowledge Economy and the Teaching Excellence Framework will constitute a set of mechanisms of perpetual pedagogical control in which the market will become a regulator of pedagogical possibilities. Rather than supporting pedagogical exploration or creating conditions for the empowerment of students and teachers, such policies support the precarisation and casualisation of both. We develop these claims through a reading of these policies alongside Gilles Deleuze's Postscript on the Societies of Control, and situating it in the context of what Gary Hall has termed postwelfare capitalism. We conclude by reaching out to others in the tertiary education sector and beyond to ask if this really is the direction we wish to take this sector in the UK.
\end{abstract}

Keywords: TEF, Deleuze, postwelfare capitalism, pedagogy, critical education policy studies

\section{Introduction}

The Teaching Excellence Framework (TEF) and the accompanying UK government White Paper, Success as a Knowledge Economy: Teaching Excellence, Social Mobility, and Student Choice (Department for Business Innovation and Skills - BIS - 2016b), pose a number of challenges to those working in the contemporary university. In this paper, we articulate some of these challenges through a reading of Gilles Deleuze's Postscript on the Societies of Control (1992) alongside this White Paper. More specifically, our first claim, made through Deleuze, is that the TEF's implementation and enforcement - as well as many of the other measures outlined in the White Paper - will constitute a set of mechanisms of perpetual pedagogical control through which the concrete everyday relations of university life will be further subjected to processes of neoliberalisation, management, control, supervision, metricisation, marketisation, casualisation and precarisation (to name only some potential effects). By 'further', we here situate this research alongside the work of others who have developed research, 


\section{TEF Special Edition}

criticism and resistance to the continuing neoliberalisation of the university in the UK and beyond (Brunskell-Evans, 2009, 2012; Harney and Morton, 2013; Heaney, 2015, 2016; Neary, 2015). The TEF is itself 'marketed' as a necessary corollary to the Research Excellence Framework (REF) and as a policy mechanism which will 'drive up the standard of teaching', providing students (in esse and in posse), employers and other education providers with 'powerful signals' about how 'excellent' teaching is being produced across the higher education sector (2016b: 13). Against this, the second argument of this paper is that these incoming reforms of the UK's tertiary education sector have little to do with improving teaching quality or enhancing student empowerment, but instead are indicative of the UK's gradual move towards what Gary Hall (2016) has aptly termed postwelfare capitalism; these reforms, in other words, we situate as reforms which help enable a transition to a tertiary education sector befitting a postwelfare neoliberal state. ${ }^{1}$

\section{Success as a Knowledge Economy}

Before making these arguments, however, we shall first devote our attention to the key claims we wish to focus on within the White Paper (the provisions from which are to be found in the Higher Education and Research Bill, which, at the time of writing, has gone through its second reading in the House of Lords and is awaiting its committee stage examination). The key claims on which we shall focus relate to (1) the White Paper's extensive policy of marketising the tertiary education sector further, a policy which, it is argued, requires (2) so-called regulatory 'simplification', and (3) extensive 'information provision' for the apparent aim of 'empowering student choice' (BIS, 2016b: 10), to which the TEF is, in part, a response. We shall explore each of these points in turn.

\section{i. (Neoliberal) Marketisation}

The first point we wish to highlight is the extent to which the White Paper reifies, glorifies, and fetishises competition and marketisation. This, of course, is not in itself unique or surprising the Browne Report (BIS, 2010) explicitly did this too - however, Success as a Knowledge Economy's ambitions on this are extensive and explicitly claim to 'go further' than previous moves towards the marketisation of the tertiary education sector. Consider the following:

\footnotetext{
${ }^{1}$ We would like to thank both anonymous peer reviewers and the copy-editor for both enriching and improving the clarity of this paper through their feedback.
} 


\section{TEF Special Edition}

Competition between providers in any market incentivises them to raise their game, offering consumers a greater choice of more innovative and better quality products and services at a lower cost. Higher education is no exception [...] But we have not made a decisive enough move to open the higher education market (BIS, 2016b: 8-9, our emphasis).

The 'decisive move' the report envisages is one in which 'market entry and exit' - that is, the ability for new degree or 'service' providers to enter the higher education 'market' and acquire 'Degree Awarding Powers' (BIS, 2016b: 10), and the potential 'exit' of these providers from the market if business proves unprofitable or slow - is simplified through the reduction of 'barriers to entry' for new potential service providers. This 'decisive move,' the White Paper claims, will combat the market privilege enjoyed by long-standing institutions (or 'incumbents') whose privilege acts as a blockage to the competition the report glorifies. Indeed, easing 'market entry and exit' is envisaged almost as a silver bullet, as a mechanism which can simultaneously drive up teaching standards, economic growth and social mobility (BIS, 2016b: 9).

Opening the future of the tertiary education sector to further marketisation through the reduction of barriers to entry and exit, it must be noted, in effect means that the 'failure' and therefore 'market exit' of education providers is envisaged as a 'natural part of a healthy, competitive, well-functioning, market' which 'the Government will not, as a matter of policy, seek to prevent [...] from happening' (BIS, 2016b: 10). Such an implicit and explicit affirmation of a neoliberal market allows the White Paper to present the proposed reforms as inclusive of the notion that future 'market exits' indicate overall 'market health.' Although an extensive discussion of this point is not possible within the confines of this paper, it is worth noting how recent, contingent and contestable the dominance of this neoliberal market-oriented language is in the context of tertiary education (Barry, 2011; Canaan, 2013; Heaney, 2015).

\section{ii. Regulation, Control}

Returning to the logic of Success as a Knowledge Economy more closely, we move on to the second point from this document that we wish to highlight. In order to create the sort of competitive market environment envisaged, what is demanded, according to the White Paper, is regulatory 'simplification' or an 'updating of the regulatory architecture.' That is, in order for there to be a 'natural' and 'healthy' market, what is required is a large amount of regulatory intervention. [The capitalist coupling of deregulatory rhetoric with actual interventionism - a far cry from any putative claims of laissez-faire - has already been conceptually developed and 


\section{TEF Special Edition}

empirically examined by, of course, Karl Polanyi (2001: 141-145) and Michel Foucault (2010: 145), amongst others.] Through such intervention, the hope the White Paper articulates is that more private firms will be able to enter the 'higher education provision market' more easily, offering 'niche' education provision to help plug 'skills shortages' (BIS, 2016b: 8). The creation of a single market regulator, the Office for Students (OfS), is central to this, a regulator that will be designed to be 'explicitly pro-competition and pro-student choice' (BIS, 2016b: 15), in part through adopting a 'risk-based approach to regulation' (BIS, 2016b: 21). As Bridget Hutter notes (2005: 2-3), the history of risk-based regulation in the UK is closely associated with the emergence of deregulatory rhetoric and policy in the 1980s and 1990s and the attendant growing prominence of private-sector styles of management. Hutter interestingly connects riskbased regulation with (1) Reagan-era US 'regulatory relief' (which was one of the four cornerstones of Reagan's economic programme) (2005: 2; also, see McGarity, 1986: 261) and (2) so-called 'new public management', a trend in public sector management focusing explicitly on performance indicators, hands-on management, continuous processes of 'modernisation' and 'rationalisation', amongst other things (Hood, 1991: 4-5).

The regulatory move towards 'risk-based approaches' entails, this is to say, a doublemovement: a decentring of the state away from provision and ownership (first movement) towards oversight and management (second movement); or, what Hutter describes as 'a move from public ownership and centralised control to privatised institutions and new forms of state regulation' (2005: 3 ). This is a decentring in so far as the state moves away from its previous role as a (depending on the context) owner, provider or main funder of a service, towards an overseer, supervisor, or manager of the industry in question. In the White Paper's vision of the future UK tertiary education sector, the level and intensity of supervision and management proffered is connected to an institution's performance in regular data monitoring mechanisms (as is already in place in, for example, the REF). For example, and to return briefly to the question of 'market exit' which we noted above, whilst the White Paper does emphasise the need for 'student protection' in the event of 'market exit' (BIS, 2016b: 22) and does claim that any 'choice' to close a particular institution will be in the hands of the institution itself (BIS, 2016b: 38), it nonetheless does not explicitly exclude the possibility of the sector regulator's pushing particular institutions towards 'market exit.' ${ }^{2}$ Instead of this, the White Paper affirms that the regulator will attempt to ensure the efficiency and swiftness of any institution-closure process (BIS, 2016b: 39) and, further, that institutions which give the regulator a 'cause for

\footnotetext{
2 We thank one of the anonymous peer reviews for this astute point.
} 


\section{TEF Special Edition}

concern' (BIS, 2016b: 34), for example, will be subject to more regular and intensive reviews, whereas 'the highest quality providers will no longer be subject to controls' (BIS, 2016b: 27) although all institutions are subject to data monitoring, of course. As part of this, the White Paper even envisages the creation of what is termed an 'enter and inspect' (BIS: 2016b: 35) piece of legislation which would enable, under certain conditions, either the sector regulator or Secretary of State to 'enter and inspect' a higher education provider. In short, the level and intensity of regulatory control of the sector will be explicitly connected to certain 'key indicators' (BIS: 2016b: 33) - for example, National Student Survey (NSS) scores, TEF rankings, graduate employment - indicators which function as epistemological tools which justify and enable high levels of individual intervention into particular institutions whose 'performance' does not meet, or is not compliant with, market demand. We shall now focus a little more closely on these epistemological tools and on the question of the 'information provision' of these 'key indicators' which the White Paper lauds for its potential for 'empowering student choice' (BIS, 2016b: 10). Our explicit focus here will be the TEF.

\section{iii. Information Provision}

The logic of the claims of Success as a Knowledge Economy, on the reading we are developing, is this: the tertiary education sector requires competition to flourish and grow; competition requires marketisation; marketisation requires reducing barriers to entry and a move to a risk-based regulatory framework; a move to risk-based regulatory framework requires oversight and management (i.e., further processes of intervention). Oversight and management, then, become the problems to be solved and these are immediately problems of control and supervision. Indeed, as Céline Baud and Eve Chiapello (2016) note, drawing on Michel Foucault (2010), and, as we have already suggested, the (decidedly neoliberal) move towards risk-based regulatory frameworks does not require 'less' intervention, but rather demands a multiplicity of new tactics of intervention, disciplinarisation and control, such as the building of new institutional incentive structures through epistemological and calculative technologies, bureaucratic expansion and so on. Control and supervision are positioned as the explicit centre-point of both the REF and TEF. The TEF will provide information and 'inform the competitive market' (BIS, 2016b: 13) about which institutions have been most compliant with the incentive structures the TEF promotes (i.e., 'teaching excellence').

The White Paper notes that OfS 'will be able to provide real-time analysis and information to the Secretary of State' (BIS, 2016b: 66) of the higher education sector and individual institutions; 


\section{TEF Special Edition}

furthermore, BIS's 'factsheet' on the Higher Education and Research Bill even speaks of this as an 'information revolution' (2016a). More information provision, of course, means more intervention, supervision and control. The clearest mechanism of control and supervision, as well as one of the largest signals to the market and students, will be the establishment of TEF league tables which will grade and rank institutions. Noteworthy is the decidedly extensive nature of these mechanisms of measurement, justified by the, to say the least, difficult epistemological task of reducing a practice as broad as teaching to a single metric:

Measuring teaching quality is difficult. But it is not impossible. We define teaching broadly - including the teaching itself, the learning environments in which it takes place, and the outcomes it delivers. Such things can be measured: students assess their satisfaction with their courses, retention rates are a good proxy for student engagement, contact hours can be measured, employers choose to sponsor some courses, or work with some institutions, because of the industry-relevance of their offerings, and employment rates can be measured. Some of these metrics are of course proxies - but they directly measure some of the most important outcomes that students and taxpayers expect excellent teaching to deliver. And we recognise that metrics alone cannot tell the whole story; they must be benchmarked and contextualised, and considered alongside the additional narrative that can establish a provider's case for excellence. Taken together, we can build a rounded picture of the teaching experience that we expect higher education to deliver to its stakeholders. (BIS, 2016b: 46)

The more extensive the epistemological task, the White Paper argues, the more that aspects of the teacher-student relationship need to be measured, supervised and thereby controlled. Once teaching practices are metricised and ranked, higher rankings will enable institutions to charge higher tuition fees which, along with the REF (and the many other prominent league tables), will further reproduce and centralise a competitive and hierarchical reputational economy between universities built around a putative commitment to 'student choice'. This is an effect the White Paper explicitly lauds (BIS: 2016b: 46); indeed, the continual establishment of hierarchies and short-term reputational competition between institutions, students and teachers is one of the explicit purposes of the TEF, rather than the sort of fundamental challenge to the privileged enjoyed by long-standing 'incumbent' institutions which we mentioned above. Competitive reputational economies, and hierarchies between institutions, students, and teachers, this is to say, constitute one of the key aims of information provision, and thus of the TEF. 


\section{TEF Special Edition}

Having outlined the components of the White Paper pertinent to our arguments in this paper, we shall now pivot to these two arguments themselves.

\section{The TEF as a Mechanism of Control}

Deleuze's arguments in his Postscript on the Societies of Control will guide this section. What Deleuze called societies of control, which he claimed were emerging at the time of the paper's publication, are distinguishable by their gradual move away from tactics of normalisation and discipline in 'enclosed' institutions such as the school, hospital, prison, and so forth (the institutions so central to Foucault's disciplinary societies), and towards new modes of normalisation or modulation in 'open' environments. Of course, for Deleuze, enclosed institutions are not totally erased, and disciplinary power is not totally replaced, by the emergence of control societies. Further, as Bernard Stiegler notes, control societies cannot be disassociated from the emergence of contemporary digital technologies (2015: 49). Deleuze identifies some institutional shifts: from the hospital to more decentralised mechanisms of care (e.g. hospices and day care); from the factory (a key site of discipline) to the corporation (a key site of control). The factory/corporation distinction, here, is worth focusing on, as it is the emergence of the contemporary corporation which is vital in the emergence of new forms of educational institutions. The corporation operates in part, for Deleuze, through practices of modulation (as, for example, in differential salary structures), which affect each actor in the institution and which ensure perpetual competition between them:

If the most idiotic television game shows are so successful, it's because they express the corporate situation with great precision [...] the corporation constantly presents the brashest rivalry as a healthy form of emulation, an excellent motivational force that opposes individuals against one another and runs through each, dividing each within (Deleuze, 1992: 4-5, our emphasis).

Crucial for our purposes are Deleuze's reflections on educational institutions, the future of which he sees as a general merging with the corporation.

Indeed, just as the corporation replaces the factory, perpetual training tends to replace the school, and continuous control to replace the examination. Which is the surest way of delivering the school over to the corporation. (ibid, 5)

Whilst one 'exits' disciplinary institutions (usually to move on to another site of enclosure) - such as the exit of the 'reformed criminal' from prisons into factories - one, in effect, never exits 


\section{TEF Special Edition}

control. Control is, for Deleuze, perpetual, limitlessly postponed from completion (ibid, 5), inciting continuous short-term competition for short-term accumulation and turnover, but whose general operation is in principle 'continuous and without limit' (ibid, 6).

A further aspect of control which is pertinent to this paper is that of how control demands supervision and oversight. Continuous and constant supervision and oversight allows for incentive structures to be continuously changeable, for rewards and punishments to be always possible. This is the crux of Deleuze's claim that 'controls are a modulation' (ibid, 4): continuous and constant supervision - rendered possible by contemporary digital technologies - allows for the continuous differentiation or modulation of the incentive structures that individuals face, how they are rewarded, punished, and so forth.

To sum the points we wish to extract from Deleuze: the move towards societies of control - as a move towards new modes of normalisation and modulation in 'open' environments - is constituted through (1) modulation and incessant competition; which is in principle (2) open, continuous, constant, and without pre-defined limits; which, in order to operate, requires (3) continuous and constant supervision and oversight. We do not presuppose any priority to these three components, nor do these three points exhaust Deleuze's claims, but they will suffice for our purposes.

Returning to Success as a Knowledge Economy and the TEF, let us revisit the rationale for further marketisation in the tertiary education sector. The White Paper, as we have already noted, reifies, glorifies, and fetishises competition and marketisation. The key condition for creating the institutional incentives for such behaviour (incessant competition and marketisation) is a vast set of epistemological mechanisms of supervision and control, mechanisms which perpetually modulate the behaviour of each individual actor insofar as the application of these epistemological mechanisms are, in principle, perpetual and unlimited and can be applied differentially; institutions which do not compliantly adapt to these incentive structures will face harsher and more radical interventions and, if necessary, the Government will 'assist' their market exit. The open-ended reputational economy which the TEF is presented as, for example, is an open mechanism of perpetual competition which is never completed. Teachers under the TEF, in this sense, will always be preparing for the next TEF and the next process of monitoring and are incentivised to adjust their behaviour according to these mechanisms of control. Institutions which do not compliantly adapt the behaviour incentivised by these incentives will not, the White Paper hopes, last long, evidenced especially in the White Paper's emphasis on 


\section{TEF Special Edition}

and, indeed, support of, 'market exit' as an apparent sign of a healthy, competitive market (BIS, 2016b: 43; 49; 53).

Transforming the regulatory and incentive structure of the tertiary education sector through lowering barriers to market entry and exit and the generation of hierarchical and reputational economies with financial 'prizes' attached (such as the potential ability to raise tuition fees when an institution achieves high TEF rankings) is the White Paper's approach of industry modulation, that is, its method of creating a more thoroughly marketised sector and generating incessant competition. The TEF is envisaged as an industry modulator, a regulatory tool comprising informational flows and signals through which to control the sector. In addition, it is important to note that, since 'competition' and 'growth' are the explicit goals of all the policies suggested in Success as a Knowledge Economy, these goals are, of course, never achieved 'once and for all'. They are, in principle, perpetual, as Jo Johnson notes in the White Paper's Foreword: 'If we are to continue to succeed as a knowledge economy, however, we cannot stand still, nor take for granted our universities' enviable global reputation' (BIS, 2016: 5). The risk-based approach to regulation is perpetual, continuous, and without limit. The state's role becomes, therefore, that of enabling informational flow and the manipulation of incentive structures through epistemological, calculative, and financial technologies; or, in other words, the state's role becomes that of continuous and constant supervision of individual and institutional 'performance' and of the relations between students and teachers as such. Insofar as such supervision and oversight, as far as the TEF is concerned, is focused on teaching practices, but in a broad sense which encompasses teaching 'environment' and therefore the teacher/student relationship as such, our claim here is that the TEF is explicitly a mechanism of perpetual pedagogical control.

\section{The University in Postwelfare Capitalism}

In The Uberfication of the University, Gary Hall uses the term postwelfare capitalism as a broad indicator to denote the coalescence of two main socio-economic trends of recent years (here we are focusing specifically on the UK): (1) privatisation, deregulation, and austerity and (2) the growth of (profit-driven) so-called 'sharing economies', which rely on contemporary digital technologies - and which are part of the growth of 'platform capitalism' (Srnicek, 2017). By way of concluding this paper, this section will offer a reading on this context of postwelfare capitalism by intersecting our reading of Success as a Knowledge Economy, alongside Deleuze, with the political-libidinal economy of the present. 


\section{TEF Special Edition}

Uberfication, broadly speaking, denotes the recent growth of these so-called 'sharing economies', which commodify human-human relations through digital sharing platforms built upon maximising the sense of consumer choice and convenience, usually through extensive rating systems for 'service providers' and rapid, digitally-enabled, service. Firms like (of course) Uber and AirBnB are treated as exemplars of this trend. An early point worth mentioning is that the majority of those who labour (and generate profit) for AirBnB, for example, are not AirBnB employees and thus do not have access to labour rights (Hall, 2016: 8-9). (It remains to be seen what effects the employment tribunal's decision, in October 2016, on Uber's losing the right to classify its drivers as self-employed in the UK will have). Nick Srnicek notes that such firms adopt a 'hyper-outsourced model' (2017: 76) and are thereby able to side-step the provision of any economic security to their workers. This is indicative of the type of casualisation of labour or precarisation of labour (Standing, 2011) - prominent in the 'sharing' or "gig economy (but which, of course, is not reducible to it), especially insofar as digital platforms allow 'gigs' to be arranged on an ad-hoc basis for the consumer (and therefore on an insecure basis for the service provider). Casualisation also denotes flexibilisation. In flexible markets, as Hall notes, 'employers want to be able to draw from a pool of part-time, hourly-paid, zero-hours and nocontract workers who are available 'on tap', often at extremely short notice' (2016: 18). In their hiring practices, employers want to ensure further, we should add, that only the 'most competitive' employees are hired to satisfy 'consumer demand'. Access to the relevant information, coupled with a reputational economy, helps employers and regulatory agencies generate such flexibilised labour conditions and produce certain incentive structures. The example of Uber is instructive here: both consumers and service-providers are subject to a ratings-based reputational economy. Microsoft-owned Linkedln, too, performs a similar function in providing employers and potential employees with instant access to a large database of 'trusted' (through their gated-access approach) potential 'networking' and employment opportunities.

Hall does not explicitly discuss the White Paper, nor the Teaching Excellence Framework. Nonetheless, as he does note, levels of casualisation in the tertiary education sector are already considerable, noting University and College Union (UCU) research which found that, when 'the use of atypical academic staff is factored in, $54 \%$ of all academic staff and $49 \%$ of all academic teaching staff are on insecure contracts', concentrated on those who have the largest teaching loads (UCU, 2016). The White Paper's measures of marketisation, including the function the TEF could feasibly play in such new conditions, we here argue must be considered alongside 


\section{TEF Special Edition}

these tendencies towards precarisation in the tertiary education sector and, as such, within the UK economy more generally (Srnicek, 2017: 79). These measures of marketisation look set to open this sector to accelerated further processes of casualisation and precarisation. Under such increasingly precarious labour conditions, the reputational economy which the TEF seeks to become (BIS, 2016b: 49), the White Paper hopes, will acquire central importance in enabling 'service-providers' (teachers) teaching 'gigs' in a new education market - a shift which would be a continuation of processes of what Charmaine Brown (2013) has termed the 'professionalisation agenda' and which she has associated with a generalised deterioriation of working conditions. The TEF's reputational economy is argued for in terms of student choice and satisfaction - wherein satisfaction is instrumentally connected with 'good outcomes' or 'employment outcomes' (BIS, 2016b: 43) - but also in terms of flexibility and a commitment to part-time study (ibid, 52). In effect, the labour market that the White Paper envisages is explicitly precarious and insecure, which, the White Paper conjectures, is a condition for 'teaching excellence':

[W] want a higher education system which is flexible enough to cope with change [...] A competitive and dynamic higher education sector needs students who actively and regularly challenge universities to provide teaching excellence and value for money. It needs institutions with the right incentives to deliver for students, to innovate, and to grow. (ibid, 53, our emphasis)

Flexible labour markets, of course, require flexible and precarious workers, or quite simply, disposable workers. Hall, in a related market (in his projection for the soon-to-be uberfied university sector), notes the following:

Increasing numbers of university workers [...] will have little choice but to sell their cheap and easy-to-access courses to whoever is prepared to pay for them in the 'alternative' sharing economy education market created by platform capitalism [...] And as such, they will experience all the problems of deprofessionalization, precarity (in the sense of being unable to control or even anticipate their own future), and continuous performance monitoring by networked surveillance technologies that such an economy brings. (Hall, 2016: 21-22, our emphasis)

In place of continuous, Hall could, of course, have also used the term perpetual. Recall the points we subtracted from Deleuze in the previous section: the move towards societies of control was positioned as a move constituted through (1) modulation and incessant competition; 
which is in principle (2) open, continuous, constant and without pre-defined limits; and which, in order to operate, requires (3) continuous and constant supervision and oversight. We treat Deleuze's claims here as instructive when considered in the light of our contemporary postwelfare capitalism and the proposed policies of the White Paper. We do so for two main reasons, which we shall now outline before concluding this paper.

First, it is of note how modulation and incessant competition is incentivised among individuals working in and between academic institutions through the pervasive rhetoric of excellence and the hierarchical and reputational economies generated through mechanisms of surveillance such as the REF (and soon, the TEF). Such incessant competition must be perpetual and openended, insofar as such open-endedness maintains an incentive structure by which academic staff 'are motivated to continuously try to do better' (Hall, 2016: 27). Achieving 'better' and producing 'excellence', in other words, become, in effect, about being controlled by short-term reputational metrics and targets - 'Control is short-term and of rapid rates of turnover, but also continuous and without limit' (Deleuze, 1992: 6). Similarly, as Srnicek notes, the reputation systems of firms such as Uber and AirBnB tend to transmit and exacerbate gendered and racialised biases (2017: 77): metrics of control are, in this sense, metrics of exclusion. In the context of postwelfare capitalism, the intensification of precarisation and reputationalism which the White Paper and the TEF seek to produce - that is, its aim of perpetual pedagogical control - looks set to transform teaching into a 'gig' to be competed for in the university-to-come. Such a transformation of the labour conditions in the tertiary education sector, coupled with a framework of control based upon a notion of 'excellence', is well suited to weakening the possibilities of solidarity, of collective organisation and therefore of key potential avenues through which such trends could be resisted and/or confronted in creative and dynamic ways. Such solidaristic possibilities are attacked through incentive structures of incessant competition, the potential exacerbation of gendered and racialised privilege and accelerating processes of precarisation.

The second point we wish to make on this context of postwelfare capitalism relates to the putative commitments to 'student choice', 'student satisfaction' and 'teaching excellence', through which Success as a Knowledge Economy makes its claims. The White Paper envisages an education market which is hyper-responsive to 'student and employer demand' and which (they conjecture) is 'more satisfying' or 'more excellent' the smoother the transition from tertiary education to employment is for students (BIS, 2016b: $5,8,9,13,19,46,58$ ). [It is also of note that TEF review boards will include 'employers', though this is not commented on in 


\section{TEF Special Edition}

any detail (BIS, 2016b: 19, 40).] Under perpetual pedagogical control, pedagogical exploration becomes totally subordinated to the production of satisfied and employable customers, as well as the transmission of hollow and dogmatic pedagogies (MacKenzie and Mackenzie, 2014). As Hall notes:

Faced by such a situation [where metrics dominate and govern] [...] academics are likely to prefer to run courses in subjects that are perceived by student debtors-as-consumers as having the potential to help them gain a 'good' job with a decent salary. They will thus be involved mainly in producing the type of unthreatening, lower-level, vocational 'workers' that are needed by postwelfare capitalism (and which the current push on the part of many governments towards an 'employability agenda' for much of higher education seems determined to generate) rather than the kind of educated public citizens or creative critical thinkers who are capable of maintaining some control over their own work and futures (Hall, 2016: 31-32).

Teachers (and, of course, potential students) who do not adapt to these conditions face, in other words, even further economic insecurity in a context of precarisation. Following the White Paper's logic, we ought not to teach those subjects which do not satisfy consumer demand (which do not produce satisfaction and employability); nor ought, it follows, education providers (temporarily) employ those individual teachers who do not produce satisfied and employable graduates. The effects such incentive structures and mechanisms of control will have on what is pedagogically possible in the university-to-come cannot be fully predicted, of course. However, as Daniel Saunders notes, speaking here of the similar pervasiveness of 'excellence', competition and precarious labour conditions in the United States tertiary education sector, excellence frameworks (such as the TEF and of course, the REF, which has been subject to similar criticism (Cabral and Huet, 2015)) are grounded on the reducibility, metrifiability and ranking of teaching practices and, as such:

Not only does this quantification necessarily challenge emancipatory educational practices that are built upon the recognition of students and faculty as nuanced, multidimensional people who are irreducible with one another (Freire, 2000; Illich, 1971), but it limits the potential for new, non-quantitatively based pedagogical practices and educational priorities. Such measurement and its corresponding closing off of alternative approaches is a foundation of the neoliberalization of postsecondary education, as everything within a neoliberal world is commensurable with one another and subject to 


\section{TEF Special Edition}

quantitative measures (Brown, 2015). As such, to embrace the commitment to excellence is to naturalize and universalize the quantification of postsecondary education [...] Once excellence is accepted as a primary educational goal, institutions must ensure that the goal is met. To do so requires building upon the quantification of all educationrelated activities and placing them within assessment regimes (Saunders, 2015: 403).

One of the threats which Saunders gestures towards in his own context, and which we wish to emphasise by way of conclusion, is that the language of student choice and excellence functions in fact as a commitment to the 'competitive market' as the arbiter of excellence and, as such, the arbiter of what is not excellent, what is legitimate (profitable) to teach and what is not so. Or, in short, a (dogmatic and uncritical) commitment to the 'competitive market' becoming the regulator of pedagogical possibilities, to the normalisation of incessant and perpetual pedagogical supervision and control, and to intensifying processes of casualisation and precarisation. It is, to say the least, difficult to identify processes - which others have with some optimism in recent years (Birch, 2012) - which support student empowerment, explorative and deep pedagogies through which students and teachers might be able to co-create empowering environments together, or the long-term economic security of either students or teachers. Success as a Knowledge Economy and the TEF, we claim, have little to do with improving teaching quality or enhancing student empowerment, but instead are significant steps towards a more thoroughly marketised tertiary education system: a tertiary education sector befitting a postwelfare neoliberal state.

\section{Conclusion}

In this paper, we have argued that Success as a Knowledge Economy and the Teaching Excellence Framework will constitute a set of mechanisms of perpetual pedagogical control in which the market will become a regulator of pedagogical possibilities. Rather than supporting pedagogical exploration and empowering students, such policies support precarisation and casualisation, and the subordination of pedagogy to market principles and truths.

We here have not suggested a particular course of action to take, in part owing to the fact that we do not wish perpetuate mechanisms of control over the myriad of as-yet unexplored possibilities of creative confrontation. Such a move would pre-emptively narrow what we cannot foresee. We understand that such confrontations could be actualised in a number of different ways and hope that the critique outlined in this paper will encourage or invite readers to carve out their own possible confrontations. Our own response, however, has already started to 


\section{TEF Special Edition}

manifest itself in creative and experimental pedagogy: an avenue that we have been exploring through workplayshops (these explorations will be the subject of our following paper on these themes). Creatively confronting the conditions we face becomes, we suggest, a pedagogical task to be participated in and explored for those interested in transforming them. This paper ends with an open narrative rather than a closed one and with more questions than answers. Do we support conditions such as these in the tertiary sector? Is it not our task to confront them? How may we mutually empower each other and support inclusive and open educational practices rather than submitting to the exclusionary logic of the market?

\section{Reference list}

Barry, J. (2011) 'Knowledge as Power, Knowledge as Capital: A Political Economy Critique of Modern 'Academic Capitalism'.' Irish Review, 43, 14-25.

Baud, C. and Chiapello, E. (2016) 'Understanding the Disciplinary Aspects of Neoliberal Regulations: The Case of Credit-risk Regulation Under the Basel Accords.' Critical Perspectives on Accounting. Available at: http://dx.doi.org/10.1016/j.cpa.2016.09.005 (Accessed: 3 December 2016).

Birch, C. (2012) 'The Road Ahead.' Compass: Journal of Learning and Teaching, 3(4).

Brown, C. (2013) 'Friend or foe! The Professionalisation Agenda: Teacher Educators In The Lifelong Learning Sector (LLS).' Compass: Journal of Learning and Teaching, 3(4).

Brown, Wendy (2015) Undoing the Demos: Neoliberalism's Stealth Revolution. New York: Zone Books.

Brunskell-Evans, H. (2009) 'When the Shift Hits the Critical Fan: A Foucauldian Analysis.' Compass: Journal of Learning and Teaching, 1(1).

Brunskell-Evans, H. (2012) 'Demystifying Theory.' Compass: Journal of Learning and Teaching, 3(4).

Cabral, A.P. and Huet, I. (2015) 'Growing Separation Between Teaching/Learning and Research - Anticipating the Impacts from REF 2014.' Compass: Journal of Learning and Teaching, 6(10). 


\section{TEF Special Edition}

Canaan, J. E. (2013) 'Resisting the English Neoliberalising University: What Critical Pedagogy Can Offer.' Journal for Critical Education Policy Studies, 11(2), 16-56.

Deleuze, G. (1992) 'Postscript on the Societies of Control.' October, 59, 3-7.

Department for Business, Innovation and Skills (2010), Securing a Sustainable Future for Higher Education: An Independent Review of Higher Education Funding and Student Finance [The Browne Report]. Available at:

https://www.gov.uk/government/uploads/system/uploads/attachment_data/file/422565/bis-101208-securing-sustainable-higher-education-browne-report.pdf (Accessed: 5 April 2017).

Department for Business, Innovation and Skills (2016a) 'Higher Education and Research Bill: Factsheet.' Available at:

https://www.gov.uk/government/uploads/system/uploads/attachment_data/file/543500/bis-16285-higher-education-research-bill-summary.pdf (Accessed: 7 December 2016).

Department for Business, Innovation and Skills (2016b) Success as a Knowledge Economy: Teaching Excellence, Social Mobility, and Student Choice. Available at:

https://www.gov.uk/government/uploads/system/uploads/attachment_data/file/523546/bis-16265-success-as-a-knowledge-economy-web.pdf (Accessed: 5 April 2017)

Foucault, M. (2010) The Birth of Biopolitics: Lectures at the Collège de France, 1978-79. Michel Senellart, ed., translated Graham Burchell. Basingstoke: Palgrave Macmillan.

Freire, P. (2000) Pedagogy of the Oppressed. New York: Bloomsbury.

Hall, G. (2016) The Uberfication of the University. Minneapolis: University of Minnesota Press.

Harney, S. and Morton, F. (2013) The Undercommons: Fugitive Planning and Black Study. Brooklyn: Autonomedia.

Heaney, C. (2015) 'What is the University today?' Journal for Critical Education Policy Studies, 13(2), 287-314.

Heaney, C. (2016) 'The Academic, Ethics and Power.' Engaging Foucault. Adriana Zaharijevic, A., Cvejić I. and Losoncz, M., eds.,Belgrade: Institute for Philosophy and Social Theory, pp. 185-201.

Hood, C. (1991) 'A Public Management for All Seasons?’ Public Administration, 69(1), 3-19. 


\section{TEF Special Edition}

Hutter, B. M. (2005) 'The Attractions of Risk-Based Regulations: Accounting for the Emergence of Risk Ideas in Regulation.' ESRC Centre for Analysis of Risk and Regulation, London School of Economics and Political Science, Discussion Paper 33.

Illich, I. (1971) Deschooling Society. New York: Marion Boyars.

MacKenzie, I. and Mackenzie, H. (2014) 'A labial art-politics.' Contention: The Multidisciplinary Journal of Social Protest, 2(1), 69-78.

McGarity, T. O. (1986) 'Regulatory Reform in the Reagan Era.' Maryland Law Review, 45 (2), 253-273.

Neary, M. (2015) 'Educative Power: the Myth of Dronic Violence in a Period of Civil War.' Culture Machine, 16, 1-28.

Polanyi, K. (2001) Origins of Our Time: The Great Transformation. Boston: Beacon Press Saunders, D. B. (2015) 'Resisting Excellence: Challenging Neoliberal Ideology in Postsecondary Education.' Journal for Critical Education Policy Studies, 13(2), 391-411.

Srnicek, N. (2017) Platform Capitalism. Cambridge: Polity Press.

Standing, G. (2011). The Precariat: The New Dangerous Class. New York: Bloomsbury Academic.

Stiegler, B. (2015) Symbolic Misery Volume 2: The Katastrophē of the Sensible, translated Norman, B. Cambridge: Polity Press.

University and College Union (2016) Precarious Work in Higher Education: A Snapshot of Insecure Contracts and Institutional Attitudes. Available at:

https://www.ucu.org.uk/media/7995/Precarious-work-in-higher-education-a-snapshot-ofinsecure-contracts-and-institutional-attitudes-Apr 16/pdf/ucu_precariouscontract_hereport_apr16.pdf (Accessed: 6 December 2016). 